\title{
Influence of Family Status and Relationships on Social Phobia among Young Adults in Nigerian Universities
}

\author{
Uzonwanne, Francis C. \\ Department of Psychology, College Of Management Sciences \\ Redeemer's University. Nigeria \\ Akpunne, Bede C. \\ Department of Psychology, College Of Management Sciences \\ Redeemer's University. Nigeria
}

\begin{abstract}
Not very much literature offers a clear review of the influence or relationship of different levels of family status on social phobia among the sufferers. It is opined that there is little doubt that people with social phobia have fewer social relationships than other people because they have been shown to have fewer friends, fewer dating and sexual relationships, and to be less likely to marry than people in the general population or even patients with other anxiety disorders. Social phobia is a debilitating psychiatric condition that is treatable but often remains undetected and untreated and without treatment, clients are at risk for complications, such as reduced quality of life, social interactions, daily functioning, and treatment adherence. This study seeks to fill the gap by investigating the influence of family and relationship status on social phobia among young adults in Nigerian universities. 400 students were surveyed from 5 universities in southwest Nigeria, two of which are private universities and the other three are public ones. The Social Phobia Inventory (SPIN) was used to collect data for the study. Findings showed adolescents from divorced homes experience significantly higher social phobia than both adolescents from monogamous and polygamous homes. Findings also show a significant difference in the social phobia of adolescents who were in a relationship and the adolescents who were not. Findings may be useful in further understanding the nature of social phobia among young adults and determining possible clinical intervention in schools.
\end{abstract}

Keywords: Social Phobia, Family Status, Relationship Status

\section{INTRODUCTION}

Social phobia is a chronic and pervasive condition affecting a variety of life areas and producing significant emotional distress (Turner, Beidel, Dancu \& Keys, 1986). Valente (2002) stated that social phobia is a debilitating psychiatric condition that is treatable but often remains undetected and untreated and without treatment, clients are at risk for complications, such as reduced quality of life, social interactions, daily functioning, and treatment adherence. Social phobia leads to more sick days, poor job performance, costly medical and emergency care visits, mental health visits, and greater reliance on disability or welfare and in the worst cases, the patient may decide that life is not worth living and consider suicide. Screening and careful assessment are the keys to detection and evaluation of social phobia (Valente, 2002). These outcomes are such that cannot be taken lightly anywhere in the world as global financial issues continue to face this generation and the ones to come. It is important that the human resources who are trained and skilled in our universities are also free of personal setbacks that will affect productivity and performance in the work sphere when social relations are challenged. It is normal for people generally to get anxious and self-conscious intermittently. For instance, 
when one is giving a speech or the individual is interviewing for a new job, people could get nervous or unsettled. Social anxiety, or social phobia, is more than just shyness or occasional nervousness. With social anxiety disorder, there is a fear of embarrassing one's self and that fear becomes so severe that one forms behaviour of circumventing circumstances that can trigger those intense moments. DSM-IV-TR defines social phobia as an anxiety disorder characterized by a strong and persistent fear of social or performance situations in which the patient might feel embarrassment or humiliation. Schneier (1991) postulates that social phobia remains among the least understood of anxiety disorders, although dramatic growth in the study of this condition over the past 5 years is yielding new information on its characteristics and treatment response. According to the Encyclopedia of Mental Disorders, generalized social phobia as a fear of most social interactions combined with fear of most performance situations, such as speaking in public or eating in a restaurant. Persons who are afraid of only one type of performance situation or afraid of only a few rather than most social situations may be described as having non-generalized, circumscribed, or specific social phobia (Mental Disorders, 2014). According to Schneier (1991), the (differentiation of phobic disorders into simple, social, and agoraphobia in DSM-IfI2 and DSM-III-R* following the findings of Marks and Gelder in the 1960s, has stimulated recognition of social phobia as a specific disorder that causes serious occupational and social impairment. In DSM-III-R, social phobia is defined by the central concept of excessive fear of scrutiny and/or embarrassment, while the feared situation may be discrete, such as public speaking, eating in public, or being observed while writing (Schneier, 1991). Social phobia, which is also known as social anxiety disorder, is a serious mental health problem in the United States and in any given year, social phobia affects 3.7\% of the American population between the ages of 18 and 54, or about 5.3 million people leaving it as the third most common psychiatric condition after depression and alcoholism (Mental Disorders). In the generalized subtype, Schneier opined that most social situations are feared, often encompassing both discrete performance situations and social interactions, such as conversing on the telephone, initiating conversation with strangers, attending a part); or meeting with an authority figure. Sufferers may either avoid the feared situations or endure them with great anxiety, while the anxiety may include symptoms of autonomic arousal, such as palpitations, sweating, trembling, and blushing (Schneier, 1991).

Patients diagnosed with social phobia have the highest risk of alcohol abuse of all patients with anxiety disorders; in addition, they suffer from worse impairment than patients with major medical illnesses, including congestive heart failure and diabetes (Mental Disorders).

\section{Social Phobia and Family Background}

Not very much literature offers a clear review of the influence or relationship of different levels of family status on social phobia among the sufferers. Analysing family factors Bracik, Krzysztof and Zaczek (2012) report that the following percentage of respondents in groups that gave the same answers, meet the criteria for SAD. $30.6 \%$ in the group not raised by both parents and $25.8 \%$ of subjects raised in a complete family. $38 \%$ of those who at least sometimes experienced unrealistically high demands, and $21.3 \%$ of those, who hardly ever experience them. $34.7 \%$ of interviewees, whose caregivers were at least sometimes abusive, and $20 \%$ of those without such experience. When it comes to the support of elders, the percentage was $30.4 \%$, in case of those, who could not have always counted on it, and respectively $20.4 \%$ in case of those, who could (Bracik et al, 2012). James and Williams (1988) report that relatives of panic patients $(\mathrm{N}=471)$, normals $(\mathrm{N}=46)$, and social phobics $(\mathrm{N}=76)$ were compared on family histories of emotional disorders. Social phobics had significantly more relatives with social phobia than panic disorder relatives $(6.6 \% \vee 0.4 \% \mathrm{P}<.001)$ and there was a trend for social phobic relatives to be greater than normals in this diagnoses $(6.6 \% \vee 2.2 \%, \mathrm{P}=0.1)$. 
Relatives of social phobics also had significantly fewer generalized anxiety disorders, panic disorders and alcohol abusers than relatives of panic disorder probands (James and Williams, 1988). These results lend further evidence toward confirming social phobia as a distinct entity and raise the possibility that it has familial components (James and Williams, 1988).

\section{Social anxiety disorder and social relationships}

Alden and Taylor (2004) opine that there is little doubt that people with social phobia have fewer social relationships than other people because they have been shown to have fewer friends, fewer dating and sexual relationships, and to be less likely to marry than people in the general population or even patients with other anxiety disorders. The same patterns are found in children with social phobia and among nonclinical socially anxious populations, for example, children with social phobia engage in fewer social interactions with classmates. Alden and Taylor (2004), report that socially anxious college students have fewer heterosexual interactions and sexual experiences than students who are not socially anxious. Socially anxious adolescents have also been reported to have fewer and less intimate friendships than their non-anxious peers (Alden and Taylor, 2004). Alden and Taylor (2004) are however of the opinion that researchers and the world know relatively little about how socially anxious people function in the close relationships they do develop. To address that issue, Alden and Taylor (2004) report Heinrichs (2003) who examined marital relationships (intimate partnerships) in patients with social phobia and found that patients with partners reported greater life satisfaction than those without partners. While more satisfied than non-partnered patients, however, they reported more marital distress than a comparison group of people with panic disorder. In the same study, Alden and Taylor (2004) also reported Wenzel (2002) who compared a small group of patients with social phobia to non-anxious controls on a variety of relationship measures. Social phobic patients reported lower levels of emotional and social intimacy and were more likely to display fearful or preoccupied adult attachment styles (Alden and Taylor, 2004). Interestingly, Wenzel (2002) found that they were also more likely to attribute the cause of negative relationship events to some stable characteristic of their spouse, which suggested they were more negative and blaming toward their partners. Davila and Beck (2002) used structured interviews to assess university students' relationships with friends, acquaintances, family, and romantic partners and social anxiety was associated with a variety of dysfunctional strategies in those relationships, including the expected strategies of non-assertiveness and avoidance of emotional expression and conflict (Alden and Taylor, 2004). One interesting finding to materialize was that socially anxious people also reported over-reliance on others, a result it was suggested that it reflects their dependence on the few relationships they have (Alden and Taylor, 2004). Moreover, over-reliance (and nonassertiveness) were found to mediate the relationship between social anxiety and chronic interpersonal stress, while socially anxious people who were excessively dependent on others and unable to assert their own needs apparently experienced more persistent social stress (Alden and Taylor, 2004). In conclusion the three studies specify that even when individuals with social anxiety build up relationships, they view those relationships as less intimate, functional, and satisfying than do people without social anxiety (Alden and Taylor, 2004).

\section{Prevalence and Epidemiology of Social Phobia}

Gren-Landell et al (2009) sampled data from a sample of 2,128 students and analyzed them. It showed a point-prevalence rate of $4.4 \%$ (95\% CI 3.5-5.2) and a significant gender difference (6.6\% girls vs. $1.8 \%$ boys, $\mathrm{P}<0.001)$. No significant differences in prevalence of probable cases emerged across the ages. At sub-threshold level, marked social fear of at least one social situation was reported by $13.8 \%$ of the total group. "Speaking in front of class" and "calling someone unfamiliar on the phone" were the most feared social situations. In the social phobia 
group, $91.4 \%$ reported impairment in the school-domain due to their social fear. Gren-Landell et al (2000) concluded that social phobia is a common psychiatric condition in Swedish adolescents, especially in girls. As impairment in the school-domain is reported to a high degree, professionals and teachers need to recognize social phobia in adolescents so that help in overcoming the difficulties can be offered.

Schneier (1991) opines that the epidemiology of social phobia has only begun to be explored. Social phobia appears to be a common disorder, with a 6-month prevalence of $0.9 \%$ to $1.7 \%$ in men, and $1.5 \%$ to $2.6 \%$ in women according to the Epidemiological Catchment Area study. The preponderance of women with social phobia in the community contrasts with most clinical samples, where about half of social phobic patients are male (Schneier, 1991). It seems that cultural or other factors cause men to be more likely to seek out treatment for social phobia. Social phobics often fail to seek treatment, either due to the fear of self-revelation inherent in the disorder, or because of the assumption that social phobic symptoms are not treatable (Schneier, 1991). Another community survey" found that while more than $20 \%$ of the general population reported some fear of embarrassment while eating, writing, speaking in public, or using public restrooms, only $2 \%$ met the disability/distress criterion required for the DSM-III$\mathrm{R}$ diagnosis of social phobia. A large proportion of the population that fears social situations does not experience intense distress or encounter circumstances that express the disability (e.g., a job that requires public speaking), so they would not receive a DSM-III-R diagnosis (Schneier, 1991).

\section{Social Phobia and School Environment}

According to the report of the National Institute of Mental Health (2009) the onset age when socio phobic symptoms begins to occur, is mainly in early adolescence. Negative experiences in childhood increase the risk of the development of SAD. The influence of education and family background is still considered to be unclear (Brook \& Schmidt 2008). Shah and Kataria (2009) opine that there is paucity of information on the epidemiology of this disorder in the developing world, especially among university students. A cross-sectional survey of students at the University of Ibadan (Nigeria) is reported, using the Composite International Diagnostic Interview (CIDI) revealed a prevalence of social phobia at 8.5\% (Shah and Kataria, 2009). Another study of 523 Swedish University students with the Social Phobia Screening Questionnaire (SPSQ) reported prevalence to be as high as 16.1\% (Shah and Kataria, 2009). Izgic et al. from Turkey found the prevalence of social phobia at $7.9 \%$ among a stratified random sample of 1,003 university students. In India, there has been only one study on social phobia (among high school adolescents) which mentions a prevalence of $12.8 \%$ and also an association with impairment in academic functioning (Shah and Kataria, 2009). Social phobia even though being a common psychiatric disorder, is under recognized and under treated. It is more common in youth, is associated with lower educational achievements, unstable employment, higher frequency of being absent to work, individuals are less likely to marry, more likely to get divorced, and have reduced productivity that can lead to dependence from family, state, society, and country. Disability in diverse functional areas and impaired quality of life are the two important domains of consequences of social phobia.

In a study of social phobia and its impact in undergraduate students (young adults) of various faculties of a University in India, Shah and Kataria (2009) found that the prevalence of social phobia varies widely among different countries. In their study, social phobia was found in $19.5 \%$ of subjects, much more than other studies among university students. Previously, when prevalence estimates were based on the examination of psychiatric clinic samples, social anxiety disorder (ie., social phobia) was thought to be a relatively rare disorder. The opposite 
was instead true; social anxiety was common, but many were afraid to seek psychiatric help, leading to an understatement of the problem. Prevalence rates may vary widely because of overlapping symptoms with other disorders. Because of the difficulty in separating social phobia from poor social skills or shyness developmentally, some studies have a large range of prevalence. In community epidemiological surveys, the prevalence of social phobia depends heavily on where the diagnostic threshold is set, ranging from $1.9 \%$ to $18.7 \% 24$. In this study, as SPIN has a specificity of $69-84 \%$ and the analysis using the disability scale suggests that between 15-20\% of those scoring above cut-off on the SPIN experienced none or mild disability (implying that they would be unlikely to reach diagnostic criteria for the disorder), it can be inferred that the prevalence rates may be somewhat lower than identified. Even after this consideration, the prevalence rate appears quite high (Shah and Kataria, 2009).

This study seeks to examine the influence of family and relationship status on the social phobia of adolescents in private and public universities in Southwest Nigeria.

\section{Statement Of Problem}

The family has always been seen as a safety net for children and adolescents as they struggle through many changes and development challenges. The adolescent is also expected to start a relationship that will become the basis of a future family also while maintaining social responsibility and exhibiting traits of a financially responsible parent and spouse. Social phobia is of major concern to society as a whole for two reasons according to the encyclopaedia on mental disorders. One reason is the disorder's very high rate of comorbidity with such other mental health problems as major depression and substance abuse. In comparison with patients diagnosed with other anxiety disorders, patients with social phobia have higher averages of concurrent anxiety disorders (1.21 versus 0.45$)$; comorbid depression or other disorders (2.05 versus1.19); and lifetime disorders (3.11 versus 2.05). The most common comorbid disorders diagnosed in patients with social phobia are major depression (43\%); panic disorder (33\%); generalized anxiety disorder (19\%); PTSD (36\%); alcohol or substance abuse disorder (18\%); and attempted suicide (23\%) (Mental Disorders, 2014). The implication to this is that we are looking at just more than a social menace here but also a catalyst to several other mental disorders that adolescents in Nigeria could be brewing up or even living with already.

The second reason is the loss to the larger society of the gifts and talents that these patients possess (Mental Disorders, 2014). Social phobia can have a devastating effect on young people's intellectual life and choice of career, causing them to abandon their educations, stay stuck in dead-end jobs, refuse promotions involving travel or relocation, and make similar selfdefeating choices because of their fear of classroom participation, job interviews, and other social interactions in educational and workplace settings (Mental Disorders, 2014). One sample of patients diagnosed with social phobia found that almost half had failed to finish high school; $70 \%$ were in the bottom two quartiles of socioeconomic status (SES); and $22 \%$ were on welfare (Mental Disorders, 2014). In addition to their academic and employment-related difficulties, people with social phobia have limited or nonexistent social support networks, so they are less likely to marry and start families of their own because of their fear of interpersonal relationships, while a number of them continue to live at home with their parents even as adults, or remain in unfulfilling relationships (Mental Disorders, 2014). This study seeks to understand how much influence the immediate family status and their relationship status also has on the social phobia adolescents are dealing with in Nigeria and especially in the university system that is producing the next generation. 


\section{Statement Of Hypothesis}

The following hypotheses are formulated to guide the data analysis and testing:

- Adolescents from monogamous homes experience significantly better socio phobic health than those from polygamous homes.

- The socio phobic health of adolescents in a relationship will be significantly different from that of adolescents who are not in a relationship.

\section{METHODOLOGY}

This study seeks to understand the influence of family and relationship status on social phobia among young adults in Nigerian universities.

\section{Research Design}

This study adopted a survey research design to examine the influence of family and relationship status on social phobia among young adults in Nigerian universities. The independent variable is Gender and School Type, while the dependent variable is Social Phobia.

\section{Research Population/ Sample}

The survey population of study is students from 5 Nigerian universities; University of Ibadan, University of Lagos, Obafemi Awolowo Unifersity Ife, Babcock University and Redeemers University. The adolescents were incidentally selected and volunteered to participate in the study.

\section{Research Instrument}

\section{SPIN - Social Phobia Inventory (Davidson, 2000)}

This is a 17 item questionnaire developed by Davidson (2000) which assesses a range of avoidance behaviors (e.g., avoidance of talking to strangers), physical symptoms (e.g., distress as evidenced by sweating) and social fears (e.g., fear of people in authority positions). The scale has good ability to distinguish adults with and without social phobia. Items assessing fear, avoidance, and physiological distress make up the three subscales of the SPIN. It has good testretest reliability; correlates highly with the Liebowitz and is more sensitive to change. The 17 items are scored from $0-4$, and are added together to give a total score with a range of 0-68.

\section{Psychometric Properties \\ Internal consistency}

Evaluation of internal consistency according to Cronbach's $\alpha$ was performed for the total baseline SPIN score, the coefficient for social phobia subjects ranged from 0.87 to 0.94 compared with 0.82-0.90 for controls groups. Coefficients for baseline subscale scores for social phobia subjects $v$. controls were as follows: fear, 0.68-0.76 v. 0.76-0.79; avoidance, 0.71 v. 0.70-0.81; and physiological, 0.70-0.73 v. 0.57-0.68. In group II at end-point, Cronbach's $\alpha$ coefficients were 0.94 for the full scale, and $0.89,0.91$, and 0.8 for the fear, avoidance, and physiological subscales, respectively.

\section{Convergent validity}

The SPIN total and sub-scale scores were compared and a highly significant correlation coefficient was obtained $(r=0.57, P<0.0001)(n=67$ at baseline). Correlation coefficients for the sub-scale items of the SPIN relative to the BSPS were also highly significant, as follows: fear subscale, $r=0.61(P<0.0001)$; avoidance subscale, $r=0.47(P<0.001)$; and physiological subscale, $r=0.66(P<0.0001)$. Correlation against the LSAS was $0.55(P<0.0001)$. 


\section{Divergent validity}

No significant correlation with the general health score of the SF-36 was found in group III $(r=0.01)$. Relative to blood-injury phobia assessed on the FQ, the correlation was $r=0.34$ $(P<0.002)$ which, although significant, was lower than the correlations noted with other social phobia measures. Relative to disability as measured by the SDS, the correlation was $r=0.33$ $(P<0.03)$.

\section{Construct validity}

Total SPIN scores for subjects with social phobia ( $n=148)$ were compared with scores for nonpsychiatric controls (group I; $n=68$ ). At baseline, subjects with social phobia had mean (s.d.) total SPIN scores of 41.1 (10.2) compared with 12.1 (9.3) in controls $(t=3.22 ; P<0.001)$.

\section{Data Collection Procedure}

The researchers obtained permission from the school authorities of Redeemer's University, University of Lagos, University of Ibadan, Obafemi Awolowo University and Babcock University to administer the psychological batteries on some of the randomly selected students of these schools. For the purpose of this study, adolescents from these five universities were surveyed and their scores in psychopathological symptoms were collected. A total of 400 students were surveyed for this study.

\section{Method Of Data Analysis}

Quantitative data was generated for this study through the administration of questionnaires. The scores obtained by the respondents will be complied into contingency tables according to the main variables under examination. The data obtained was analyzed using both descriptive and inferential statistical methods (t-Test, standard deviation, mean, range and percentage count) with the data subjected to appropriate statistical analyses and tested at 0.05 level of significance.

\section{Descriptive Statistical Analysis:}

Mean and standard deviation were used to summarize the participant's scores for Socio Phobic health based on gender, and school environment.

\section{Inferential Statistical Analysis:}

The collected data was analyzed with the aid of SPSS 22 (The Statistical Package for Social Science); Independent Sample t-Test and One-Way ANOVA was used to test the hypothesis at 0.05 level of significance.

\section{Socio Demographic Data}

\section{DATA ANALYSIS AND RESULTS}

The demographic characteristics of the respondents in the studied population and variables like gender, and school type are analyzed and presented.

There were 400 respondents from five universities surveyed on this study. From the Table the gender distribution shows that 157 of the respondents are male and 243 are female and they have on average of 37.35 and 37.95 respectively on their socio phobic health scores with a standard deviation of 11.88 and 12.9 respectively. The school type distribution shows that 146 of the respondents are from a private university and 254 are from a public university and they have on average of 37.13 and 38.04 respectively on their socio phobic health scores with a standard deviation of 10.67 and 12.79 respectively. 
Table 1: Demographic Characteristics of Participants

\begin{tabular}{|c|c|c|c|c|}
\hline \multicolumn{2}{|c|}{ VARIABLES } & NUMBER & MEAN & SD \\
\hline \multirow{2}{*}{ Gender } & Male & 157 & 37.35 & 11.88 \\
\cline { 2 - 5 } & Female & 243 & 37.95 & 12.19 \\
\hline \multirow{2}{*}{ School Type } & Private & 146 & 37.13 & 10.67 \\
\cline { 2 - 5 } & Public & 254 & 38.04 & 12.79 \\
\hline
\end{tabular}

\section{Test Of Hypotheses}

The results for the two hypotheses tested for this study are presented in this section. The Oneway ANOVA and the t-Test statistics were utilized for both hypotheses.

\section{Hypothesis One}

There will be a significant difference in the social phobia of adolescents based on their different family status. A One-way Analysis of Variance (ANOVA was used to determine if there would be a difference in the socio phobic scores of university adolescents from monogamous, polygamous and divorced family backgrounds. The independent variable represented the three different family status, while the dependent variable was the adolescents social phobia scores. See Table 4.3 for the means and standard deviations for each of the three groups of family status.

Table 2: Means and Standard Deviations of Standardized Test Scores

\begin{tabular}{lccc} 
Method_ & $n$ & Mean_ & $S D$ \\
Monogamous & 297 & 36.83 & 24.22 \\
Polygamous & 39 & 36.74 & 16.82 \\
Divorced & 64 & 42.39 & 13.96 \\
Total & 400 & 37.71 & 12.06 \\
\hline
\end{tabular}

An alpha level.05 was used for all analyses. Table shows the analysis of variance for the Social Phobia scores of the adolescents based on their family status.

Table 4.4 Analysis of Variance For SPIN Scores

\begin{tabular}{llllll} 
Source & $S S$ & $d f$ & $M S$ & $F$ & $P$ \\
Between & 1665.93 & 2 & 832.962 & 5.864 & .003 \\
Within & 56391.59 & 397 & 142.044 & & \\
Total & 58057.51 & 399 & & & \\
\hline
\end{tabular}

An ANOVA revealed a significant difference in the Social Phobia of the university adolescents based on their family status at the $p>.05$ level for the three conditions $[F(2,397)=5.864, p=$ .003]. Post hoc comparisons using the Tukey HSD test indicated that the mean score for the Social Phobia of adolescents from monogamous families $(M=36.83$, SD $=11.16)$ was not significantly different from that of adolescents from polygamous families $(\mathrm{M}=36.74, \mathrm{SD}=$ 12.87). Both groups of adolescents from monogamous and polygamous families were however 
significantly different from that of adolescents from divorced family status $(M=42.39, \mathrm{SD}=$ 14.47) $\mathrm{p}=.002$ and $\mathrm{p}=.053$ respectively. Taken together, these results suggest that monogamous family status and polygamous family status do not influence social phobia more than the other. It also suggests that if social phobia has origins from the family status, then the origins are the same in monogamous families as it is in polygamous families. The results also suggest strongly that children from divorced and separated backgrounds are much more prone to and actually suffer social phobia more than the other family types. Specifically, the results suggest that divorce is a societal menace as regards the mental health and specifically social phobia of the current and coming generation.

\section{HYPOTHESIS TWO}

The socio phobic health of adolescents in a relationship will be significantly different from that of adolescents who are not in a relationship.

Table 5: t-Test Table for adolescents relationship status and social phobia health

\begin{tabular}{|l|l|l|l|l|l|}
\hline RELATIONSHIP STAT. & N & MEAN & SD & T & P \\
\hline RELATIONSHIP & 60 & 43.28 & 13.74 & & \\
\cline { 1 - 3 } SINGLE & 340 & 36.73 & 11.48 & -3.949 & $>.05$ \\
\hline
\end{tabular}

The data analysis shows that there were 60 respondents who were in a relationship and 340 respondents who not in a relationship, while the mean social phobia scores were 43.28 and 36.73 respectively. The two-tailed $\mathrm{p}$ value associated with this test was .001 . The t-Test succeeded in revealing a statistically reliable difference between the mean number of social phobia scores that the adolescents in a relationship have $(\mathrm{M}=43.28, \mathrm{~s}=13.74)$ and that the adolescents who are not in a relationship have $(\mathrm{M}=36.73, \mathrm{~s}=11.48), t(398)=-3.949, p=.000$, $\alpha=.05$. Since the $\mathrm{p}$ value is less than .05 , it can be therefore concluded that the students in a relationship manifested a significantly higher level of socio phobic symptoms than that of the students who were not in a relationship.

\section{DISCUSSION}

The objectives of the study were to examine the influence of family and relationship status on the social phobia of young adults in Nigerian universities.

The result from the first hypothesis which states that there will be a significant difference in the social phobia of adolescents based on their different family status however showed interesting significant differences in the social phobia analysis. There was no significant difference in the social phobia of adolescents from monogamous family structure and those from polygamous family structure. There was however a significant difference in the social phobia of adolescents from divorced homes and adolescents from monogamous homes and a significant difference in the social phobia of adolescents from divorced homes and those from polygamous family structure with the adolescents from divorced homes showing a much higher social phobia health level than the other two. Even though there is a dearth of literature specifying the role of family environment on social phobia, Beesdo et al. (2009) postulates that several studies showed associations between life events and anxiety disorders. For example, in the EDSP study, preceding DSM-IV defined traumatic events predicted subsequent anxiety and depressive disorders. It has been suggested that experience of threat events tend to precede 
anxiety disorder, whereas loss events tend to precede depression. In a study that examined the relationship between parental loss before age 17 years and adult pathology in female same-sex twins from a population-based registry it was reported that increased risk for GAD was associated with parental separation. Increased risk for phobia was associated with parental death but not parental separation (Beesdo et al., 2009). This study however finds that parental separation in terms of divorce has a significant influence on adolescents social phobia. A double study was done by Elbedour, William and Hektner (2007).

The primary goal of these two reported studies was to compare the adolescents from monogamous and polygamous households on a number of mental health variables to determine if the adolescents coming from monogamous families differed significantly from their cohorts coming from polygamous families. Data were collected from Bedouin Arab adolescents living in the southern region of Israel. The findings from Study 1 demonstrate that the two groups (monogamous and polygamous) did not differ significantly on most of the assessed variables, although there were differences obtained between groups on some of the measures (Elbedour et al., 2007). This is quite consistent with the findings from this study also. Elbedour et al. (2007) report that no specific differences were found between adolescents coming from polygamous or monogamous families in terms of anxiety, depression, hostility or Global Severity Index (GSI), although children coming from homes where the father was married to three or four wives appeared to display more psychopathological symptoms than monogamous families. Adolescents from monogamous families reported more family cohesion than their peers from polygamous families (Elbedour et al., 2007). Findings from Study 2 demonstrate that the two groups did not differ significantly on teacher-perceived student mental health problems and on a measure of anxiety while the findings from Study 2 seem to support the findings from Study 1, concluding that monogamous and polygamous families in the Bedouin Arab community were far more similar than they were different (Elbedour et al., 2007).

The result from the second hypothesis which states that the socio phobic health of adolescents in a relationship will be significantly different from that of adolescents who are not in a relationship showed a significant difference between both groups. Alden and Taylor (2004) opine that there is little doubt that people with social phobia have fewer social relationships than other people because they have been shown to have fewer friends, fewer dating and sexual relationships, and to be less likely to marry than people in the general population or even patients with other anxiety disorders. This was found to be consistent with the findings of this study which show that of the 400 adolescents surveyed, about 340 of them were not in a relationship with only 60 being in one. The age of these adolescents is the age when most seek out a partner and get into some kind of relationship. The same patterns are found in children with social phobia and among nonclinical socially anxious populations, for example, children with social phobia engage in fewer social interactions with classmates. Alden and Taylor also report that socially anxious college students have fewer heterosexual interactions and sexual experiences than other students and socially anxious adolescents have fewer and less intimate friendships than their non-anxious peers.

With this in consideration, the findings of this study report a higher average of social phobia scores on adolescents in a relationship than adolescents who are not in a relationship. Alden and Taylor (2004) are therefore of the opinion that researchers and the world know relatively little about how socially anxious people function in the close relationships they do develop. To address that issue, Alden and Taylor report Heinrichs (2003) who examined marital relationships (intimate partnerships) in patients with social phobia and found that patients 
with partners reported greater life satisfaction than those without partners. While more satisfied than non-partnered patients, however, they reported more marital distress than a comparison group of people with panic disorder. This could explain the fact that despite the fact that these adolescents who manifest high social phobia are in a relationship, they still have higher levels of relationship oriented stress.

\section{CONCLUSION}

The influence of family and relationship status on social phobia among young adults in Nigerian universities is brought into focus in this study. Hypothesis focusing on comparison of social phobia scores among these adolescents based on family status, monogamous, polygamous, divorced and separated backgrounds, and their relationship status are tested in this study. 400 adolescent respondents from five Nigerian universities, two private and the others public were incidentally sampled and data collected were subjected to descriptive statistics, t-Test and ANOVA statistics. From the analysis and interpretation of results, it may be concluded that divorced and separated family backgrounds contribute highly to social phobia among adolescents when compared to adolescents from both monogamous and polygamous family backgrounds.

There was a higher significance however between monogamous and divorced/separated family backgrounds than the significance between polygamous and divorced/separated family backgrounds even though the averages where quite similar. More emphasis should be laid on studying the influence of polygamy on the social and mental health of children in this family status. Relationship status was also found to have a significant difference in social phobia health of these adolescents. Interestingly, the adolescents in a relationship were found to experience higher social phobia than those who were not in a relationship. This was however consistent with existing literature which suggests that people suffering from social phobia who are in a relationship find it more challenging to cope with relationship related stress, hence the higher level of manifestation of social phobia.

\section{RECOMMENDATION}

The following recommendations are made from the finding of this study to parents, school counselors and authorities, researchers and other professionals and/or experts who work with adolescents.

Parents must be aware of the fact that there is a prevalence of social phobia manifesting in a lot of adolescents and must also be aware of the influence of the different family status on their children's mental and social health. Decisions to separate or get divorced must be considered with the children's health in mind. Parents, whether from a sound family background or not, must find a way to incorporate psychological health check-ups alongside regular health checkups.

School counselors and authorities must also be aware of this influence of family and relationship status on the socio phobic health of adolescents so as to be better informed during history building and diagnosis of adolescents when they come in for general check-ups. This is assuming that such check-ups are incorporated in the health programmes of Universities in Nigeria. Authorities must be aware of this prevalence which impact adolescent depression and drug use and find ways to target prevention.

Parents should become more educated about the warning signs of psychological ill-health like social phobia in their adolescents. 


\section{References}

[1] Alden, L. E. \& Taylor, C. T. (2004). Interpersonal processes in social phobia. Clinical Psychology Review, 24(7), $857-882$

[2] Alden, L. E. \& Wallace S. T. (1995). Social phobia and social appraisal in successful and unsuccessful social interactions. Behaviour Research and Therapy, 33 (5): 497-505

[3] Beesdo, K., Knappe, S., \& Daniel S. Pine, D. S. (2009). Anxiety and anxiety disorders in children and adolescents: Developmental issues and implications for DSM-V. The Psychiatric clinics of North America 32(3): 483-524

[4] Bracik, J., Krzysztof, K. And Zaczek, A. (2012). Impact of family and school environment on the development of social anxiety disorder: a questionnaire study. Psychiatria Danubina, 24,(1), pp 125-127

[5] Bögels, S. M. \& Brechman-Toussaint, M. L. (2006). Family issues in child anxiety: Attachment, family functioning, parental rearing and beliefs. Clinical Psychology Review(26) 7: $834-856$

[6] Bourdon, K. H., Boyd, J. H., Rae, D. S., Burns, B. J., Thompson, J. W., Locke, B. Z. (1988). Gender differences in phobias: Results of the ECA community survey. Journal of Anxiety Disorders 2 (3):227-241

[7] Brook, C. A. \& Schmidt, L. A. (2008). Social anxiety disorder: A review of environmental risk factors. Neuropsychiatr Dis Treat, 4:123-43.

Caster, J. B., Inderbitzen, H. M., \& Debra Hope, D. (1999). Relationship between youth and parent perceptions of family environment and social anxiety. Journal of Anxiety Disorders (13) 3: 237-251

[8] Davila, J., \& Beck, J.G.(2002). Is social anxiety associated with impairment in close relationships? A preliminary investigation. Behavior Therapy, 33 (2), pp. 447-464

[9] Gren-Landell M., Tillfors, M., Furmark, T., Bohlin, G., Andersson, G., \& Svedin, C. G. (2009). Social phobia in Swedish adolescents: prevalence and gender differences. Social Psychiatry and Psychiatric Epidemiology, 44(1):1-7

[10] Heinrichs, N. (2003, September). Does a partner matter? Paper presented at the European Congress of Behavioural and Cognitive Therapy, Prague, Czechoslovakia.

[11] Hudson, J. L. \& Rapee, R. M. (2000). The origins of social phobia. Behavior Modification, 24(1) 102-129

[12] James Reich, J. \& William, Y. (1988). Family history of psychiatric disorders in social phobia. Comprehensive Psychiatry 29, (1), 72-75

[13] McLean, C. P., Asnaani, A., Litz, B. T., Hofmann, S. G. (2011). Gender differences in anxiety disorders: prevalence, course of illness, comorbidity and burden of illness. Journal of

Psychiatry Reviews, 45(8):1027-35

[14] Mental Disorders (2014). Social phobia. Encyclopedia of Mental Disorders. Retrieved from http://www.minddisorders.com/Py-Z/Social-phobia.html

[15] Montesi, J. L., Conner, B. T., Gordon, E. A., Fauber, R. L., Kim, K. H., \& Heimberg, R. G. (2013). On the relationship among social anxiety, intimacy, sexual communication, and Archives of Sexual Behavior, 42(1), 81-91. sexual satisfaction in young couples.

[16] National Institute of Mental Health (2009). The numbers count: Mental disorders in America. NIMH, 2009.

[17] Ranta, K., Kaltiala-Heino, R., Koivisto, A. M., Tuomisto, M. T., Pelkonen, M., \& Marttunen, M. (2007). Age and gender differences in social anxiety symptoms during adolescence: The Social Phobia Inventory (SPIN) as a measure. Psychiatry Research 153(3): 261-270

[18] Schneier, F. R. (1991). Social Phobia. Psychiatric Annals 21(6), 349-353

[19] Shah, P., \& Kataria, L. (2009). Social phobia and its impact in Indian university students. The Internet Journal of Mental Health, 6 (2).

[20] Stein, M. B., Chartier, M. J., Hazen, A. L., Kozak, M. V., Tancer, M. E., Lander, S., Furer, [21] P., Chubaty, D. \& Walker, J. R. (1998). A direct-interview family study of generalized social phobia. American Journal of Psychiatry, 155(1):90-7. 
[22] Turner, S. M., Beidel, D. C., Dancu, C. V. \& Keys, D. J. (1986). Psychopathology of social phobia and comparison to avoidant personality disorder. Journal of Abnormal Psychology, 95(4), 389-394.

[23] Turk, C. L., Heimberg, R. G., Orsillo, S. M., Holt, C. S., Gitow A., Street, L. L., Schneier, F. R., Liebowitz, M. R. (1998). An investigation of gender differences in social phobia. Journal of Anxiety Disorder. 12(3):209-23.

[24] Valente, S. M. (2002) Social phobia. Journal of the American Psychiatric Nurses Association 8,

(3) $67-75$

[25] Wenzel, A. (2002). Characteristics of close relationships in individuals with social phobia; a preliminary comparison with nonanxious individuals. In J.H. Harvey, A. Wenzel (Eds.), Maintaining and enhancing close relationships: A clinician's guide, Lawrence Erlbaum Associates, Mahwah, NY, pp. 199-213 